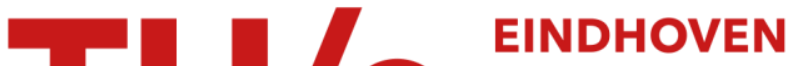

\section{Modeling of replacement alternatives for power transformer populations}

Citation for published version (APA):

Schijndel, van, A., Wouters, P. A. A. F., \& Wetzer, J. M. (2012). Modeling of replacement alternatives for power transformer populations. IEEE Transactions on Power Delivery, 27(2), 506-513.

https://doi.org/10.1109/TPWRD.2011.2181541

DOI:

10.1109/TPWRD.2011.2181541

Document status and date:

Published: 01/01/2012

Document Version:

Publisher's PDF, also known as Version of Record (includes final page, issue and volume numbers)

Please check the document version of this publication:

- A submitted manuscript is the version of the article upon submission and before peer-review. There can be important differences between the submitted version and the official published version of record. People interested in the research are advised to contact the author for the final version of the publication, or visit the $\mathrm{DOI}$ to the publisher's website.

- The final author version and the galley proof are versions of the publication after peer review.

- The final published version features the final layout of the paper including the volume, issue and page numbers.

Link to publication

\section{General rights}

Copyright and moral rights for the publications made accessible in the public portal are retained by the authors and/or other copyright owners and it is a condition of accessing publications that users recognise and abide by the legal requirements associated with these rights.

- Users may download and print one copy of any publication from the public portal for the purpose of private study or research.

- You may not further distribute the material or use it for any profit-making activity or commercial gain

- You may freely distribute the URL identifying the publication in the public portal.

If the publication is distributed under the terms of Article 25fa of the Dutch Copyright Act, indicated by the "Taverne" license above, please follow below link for the End User Agreement:

www.tue.nl/taverne

Take down policy

If you believe that this document breaches copyright please contact us at:

openaccess@tue.nl

providing details and we will investigate your claim. 


\title{
Modeling of Replacement Alternatives for Power Transformer Populations
}

\author{
Arjan van Schijndel, Student Member, IEEE, Peter A. A. F. Wouters, and Joseph M. Wetzer
}

\begin{abstract}
The age of the majority of power transformers installed in the western electricity network reaches 30 to 60 years and replacement on short term seems eminent. A technically sound policy concerning the replacement of these assets requires a model that estimates the life expectancies of individual components and from that calculates parameters related to the behavior of a population of assets as a whole. A probabilistic approach is adopted and is applied to thermal degradation of the transformer paper insulation. In this paper, we will focus on the determination of the population reliability from individual reliabilities. These individual reliabilities are based on Arrhenius modeling of paper insulation degradation, including the inherent uncertainty in the parameters involved. A statistical failure model is used to obtain the population reliability figures. The modeling method is demonstrated on two populations of power transformers in The Netherlands to evaluate the different replacement alternatives. Using the model, strategies can be defined to maximize transformer utilization and postpone replacement. The downside is the need to replace the complete fleet in a relatively short time afterwards.
\end{abstract}

Index Terms-Life estimation, maintenance, paper insulation, power system reliability, power transformer insulation, power transformers, reliability modeling.

\section{INTRODUCTION}

I $\mathrm{N}$ ELECTRICAL power transmission and distribution networks, power transformers represent a crucial group of assets both in terms of reliability and of investments. The major concerns which drive asset managers to decisions are related either to the age of equipment or to the power demands that have increased over the years. In order to safeguard the required quality at acceptable cost, it is of great importance to base decisions on a reliable forecast of future behavior. In this paper, we focus on forecasting power transformer reliability or, more accurately, on forecasting the power transformer fault probability. We employ a predictive model which involves three essential ingredients: reliability engineering, physical understanding of the degradation process, and actual knowledge of the present condition [1]. The core of the model is a generic description of aging

Manuscript received June 14, 2010; revised November 09, 2011; accepted December 17, 2011. Date of publication January 31, 2012; date of current version March 28, 2012. This work was supported in part by KEMA Nederland B.V., in part by Enexis B.V., and in part by Stedin B.V. Paper no. TPWRD00451-2010.

A. van Schijndel was with the Faculty of Electrical Engineering, Eindhoven University of Technology, Eindhoven $5600 \mathrm{MB}$, The Netherlands. He is now with the Liander N.V., Duiven 6920 AB, The Netherlands (e-mail: arjan.van. schijndel@alliander.com).

P. A. A. F. Wouters is with the Faculty of Electrical Engineering, Electrical Energy Systems, Eindhoven University of Technology, Eindhoven 5600 MB, The Netherlands (e-mail: p.a.a.f.wouters@tue.nl).

J. M. Wetzer is with the KEMA Nederland B.V., Arnhem 6800 ET, The Netherlands (e-mail: jos.wetzer@kema.com).

Digital Object Identifier 10.1109/TPWRD.2011.2181541 processes that allows one to predict lifetime in terms of future condition and reliability. The model is applied to a single degradation process: ageing of the transformer winding insulation [2]-[9]. Other subcomponents (e.g., bushings and tap-changers) can be included as well [10].

In the current western electricity network, the majority of the components are installed between 1950 and 1980, the ages thereby varying between 30 and 60 years. Replacement on short term seems to be imminent and utilities are confronted with the following questions:

- What is the life expectancy or reliability of individual components?

- How do failure probabilities cumulate to a replacement wave?

- (How) can the expected replacement wave be managed?

Proper maintenance and proactive grid upgrade increases the expected remaining life of individual transformers and, as a consequence, the reliability of the population as a whole. The individual reliabilities allow selecting the most endangered assets, and the load, maintenance, and replacement policy can be adjusted and fine tuned. The effectiveness of the measures taken can be extracted from the population probabilities.

In earlier work, a modeling approach for individual transformers was presented based on the mechanical strength of the paper insulation [1]. In Section II, this model is briefly summarized and applied to a machine transformer from which actual data were available. Starting from the individual reliability distributions, a method for forecasting the population reliability from the individual reliabilities is described in Section III, [11], [12]. The technique is applied to populations of transformers of two utilities in The Netherlands. The ultimate goal is to provide an optimization tool for maintenance replacement scenarios. In Section IV, two case studies to study the effect of different replacement strategies are presented. Section V discusses the practical model implementation and in Section VI, conclusions are drawn.

\section{INDIVIDUAL TRANSFORMER RELIABILITY}

The individual reliability is determined in a three-step process and is based on the mechanical strength of the transformer insulation paper. In the first step, the degree of polymerization of the cellulose chains, DP-value, and its threshold value at which failure is imminent to occur are determined. Next, the uncertainties of these values are incorporated. During the final step, the reliability from the DP value and its uncertainty are calculated. These steps are summarized in Section II-A. In Section II-B, the model is applied to an industrial transformer which suffered a fatal failure and was subjected to extensive investigation. 


\section{A. Transformer Reliability Model}

The decline in DP value is a result of a cascaded chemical reaction resulting in the scission of the cellulose chains. A simplified temperature dependency model of the DP value is given by the Arrhenius relation, as is extensively discussed in [4]-[7]. This has led to the following relation:

$$
\frac{1}{\mathrm{DP}(t)}-\frac{1}{\mathrm{DP}(0)}=\int_{0}^{t} k(\tau) d \tau
$$

where $\mathrm{DP}(t)$ is the $\mathrm{DP}$ value at time $t, \mathrm{DP}(0)$ is the initial DP value, and $k(t)$ is the time-dependent reaction rate. The reaction rate has the Arrhenius form

$$
k(t)=A \exp \left(-\frac{E_{a}}{R_{g} T(t)}\right)
$$

where $E_{a}$ is the molar activation energy, $R_{g}$ is the universal gas constant, $A$ is a process constant, and $T$ is the absolute temperature. For $T$, the hotspot value of the IEC loading guide [8] is used (see the Appendix). The steady-state hotspot temperature is given by

$$
\theta_{h}=\theta_{a}+\Delta \theta_{\mathrm{or}}\left(\frac{1+R I^{2}}{1+R}\right)^{x}+\Delta \theta_{\mathrm{hr}} I^{y}
$$

where $I$ is the time-dependent relative load per unit. The other input parameters are: oil exponent $x$, winding exponent $y$, loss ratio $R$, ambient temperature $\theta_{a}$, hotspot to top-oil gradient $\Delta \theta_{\mathrm{hr}}$, and top-of-tank oil rise $\Delta \theta_{\mathrm{or}}$.

For determining the uncertainty, an error estimation technique is used, resulting in (2) in

$$
\frac{\Delta k}{k}=\sqrt{\left(\frac{\Delta A}{A}\right)^{2}+\left(\frac{\Delta E_{a}}{R_{g} T}\right)^{2}+\left(\frac{\Delta E_{a} \Delta T}{R_{g} T^{2}}\right)^{2}}
$$

where the $\Delta$ 's indicate the uncertainties in the corresponding variables.

The reliability is obtained by integration of all DP values, indicated with $\nu$, according to

$$
R_{i}(t)=1-\int P_{\mathrm{th}}(\nu) p_{\mathrm{dp}}(\nu, t) d \nu .
$$

Here, $p_{\mathrm{dp}}$ is the distribution function of the DP value and $P_{\mathrm{th}}$ is the probability that the transformer has failed with a specific DP value. In this case, we use truncated normal distributions with mean $\mu$ equal to the DP value on time $t$, and $\sigma$ equal to the uncertainty value. The truncation restricts the distribution domain to values between one and the DP value for new paper. For the DP threshold, paper insulation has a critical condition around a DP value of 250 [8], [9]. An uncertainty of $10 \%$ in this value is assumed (see Section VI).

\section{B. Machine Transformer Example}

In 1992, an industrial transformer was installed at an aluminum plant. The transformer parameters are a rated power of $105 \mathrm{MVA}$, a rated primary voltage of $141 \mathrm{kV}$, and secondary
TABLE I

Thermal Characteristics OF A MACHINE TRANSFORMER

\begin{tabular}{lccccc}
\hline Cooling & $R$ & $\Delta \theta_{o r}\left({ }^{\circ} \mathrm{C}\right)$ & $\Delta \theta_{h r}\left({ }^{\circ} \mathrm{C}\right)$ & $x$ & $y$ \\
\hline ONAF & 5.7 & 48 & 14.3 & 0.9 & 1.6 \\
\hline
\end{tabular}
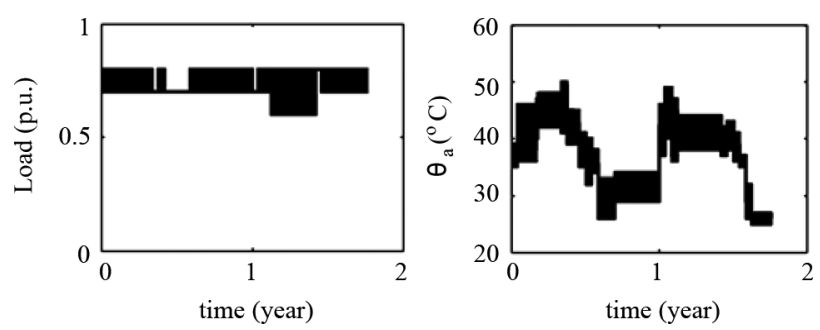

Fig. 1. Load pattern and ambient temperature of the machine transformer used for estimating the DP value in Fig. 2.

TABLE II

Data to Calculate the MeAn Residual Life of KRAFT AND Thermally UPGRADED PAPER, ACCORDING TO [4] AND [6]

\begin{tabular}{ccccc}
\hline \multicolumn{2}{l}{ Winding insulation paper } & $A\left(\right.$ hour $\left.^{-1}\right)$ & $E_{a}(\mathrm{~kJ} / \mathrm{mol})$ & $D P(0)$ \\
\hline \multirow{2}{*}{ Kraft } & Emsley & $1.07 \cdot 10^{8}$ & & \\
& Lundgaard & $2.0 \cdot 10^{8}$ & \multirow{2}{*}{111} & 1000 \\
\hline Thermally & Emsley & $0.37 \cdot 10^{8}$ & & \\
upgraded & Lundgaard & $0.67 \cdot 10^{8}$ & & \\
\hline
\end{tabular}

voltage of $10.5 \mathrm{kV}$, an operating frequency of $50 \mathrm{~Hz}$, and oil natural air-forced (ONAF) cooling. Its thermal parameters are listed in Table I. The transformer was subjected to an extensive investigation after it failed in 2007 due to a winding short circuit. The presence of corrosive sulfur in the oil was identified as the failure cause. Although the transformer did not fail directly by a low tensile strength of the paper-oil insulation, data on the actual hotspot DP value became available and are used to evaluate the model.

The transformer winding insulation material is Kraft paper, with the depolymerization reaction rate figures given in Table II. New Kraft paper has an initial DP value of 1200 , but after drying, the DP value drops to about 1000 . For this transformer, the data on load pattern and ambient temperature were recorded as two hourly values measured on 24 days. These data were available for a limited number of days, spread over a period of almost two years. The measured daily patterns are duplicated up to the missing days until the next sample day. Both this two-yearly load pattern and the ambient temperature profile are assumed to be representative for the transformer's complete life, and are also taken for the missing years. Their maximum and minimum values are plotted for a two-year period in Fig. 1. The hotspot temperature according to (3) reaches a value of $93{ }^{\circ} \mathrm{C}$ at maximum load and ambient temperature.

Fig. 2(a) shows the model results obtained with the value of the $A$ parameter suggested by Emsley [4]. For Fig. 2(b), the $A$ value suggested by Lundgaard [6] is taken. The expected DP values are represented by the solid lines. The dotted lines define the one $\sigma$ (standard deviation) confidence bound, representing a $68 \%$ probability margin. For the uncertainties, a value of $0.5 \mathrm{~kJ} / \mathrm{mol}$ is taken for the activation energy and a relative 

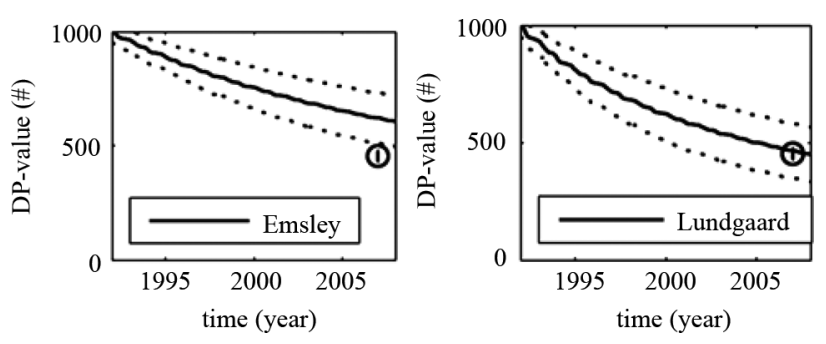

Fig. 2. Machine transformer paper DP value calculated for Kraft paper degradation according to parameters obtained from [4] (left) and [6] (right). The circle indicates the lowest DP value of all analyzed samples. The dotted lines are the $68 \%$ error margin of the simulated result.

error of $10 \%$ in $A$, based on the precision with which the corresponding quantities were specified (see Section VI). The calculated DP value at the time of failure, using data from [4] is 622 with a standard deviation of $18 \%$ at the time of failure. Using data from [6], a DP value of 468 with a standard deviation of $25 \%$ is obtained. The actual measured DP value of $454 \pm 23$ is indicated in the plot as well. Both predicted curves have a high uncertainty. This is due to the inaccuracies in the load, ambient temperature, and the transformer characteristics. The actual uncertainty may even be higher, because of the uncertainties in the extrapolation procedure of the load and ambient temperature. The measured DP value agrees with both simulations considering their error bounds.

\section{TRANSFORMER POPUlation Reliability}

The population model and the population reliability parameters used in this paper are introduced in Section III-A. First, the individual transformer reliabilities are combined; next, a population reliability parameter is extracted. The concept is illustrated on a combined transformer fleet of two Dutch utilities in Section III-B.

\section{A. Population Reliability Model}

The individual reliability results, as described in Section II, can be used to obtain the transformer population reliability. The method assumes that the individual reliabilities $R_{i}$ and, consequently, the failure probabilities $F_{i}=1-R_{i}$, are uncorrelated. The probability that exactly $j$ transformers from a population of $N$ fail, and the probability that less than $m$ failures have occurred at time $t$ is given by [11] and [12]

$$
\begin{aligned}
P_{F}^{(j, N)}(t)= & \sum_{i_{1}=1}^{N} F_{i_{1}}(t) \sum_{i_{2}>i_{1}}^{N} F_{i_{2}}(t) \cdots \\
& \sum_{i_{j}>i_{j-1}}^{N} F_{i_{j}}(t) \prod_{i \neq\left\{i_{1} \cdots i_{j}\right\}}^{N} R_{i}(t) \\
R^{(N-m+1, N)}(t)= & \sum_{j=0}^{m-1} P_{F}^{(j, N)}(t) .
\end{aligned}
$$

The superscript $(N-m+1, N)$ indicates that at least $N-$ $m+1$ out of $N$ transformers are still operational. It is clear that with large populations $N$ and a significant number of failures $m$, a direct evaluation of the equations above is elaborate, due to the number of possible combinations. A far more efficient approach is to apply a pivotal decomposition by considering the following recurrent relation:

$$
R^{(i, j)}(t)=\left(1-R_{j}(t)\right) \cdot R^{(i, j-1)}(t)+R_{j}(t) \cdot R^{(i-1, j-1)}(t) .
$$

The probability that at least $i$ out of a set of $j$ transformers are operational is equal to the probability that the "last" transformer $j$ has failed and from the remaining $j-1$, at least $i$ transformers work, plus the probability that transformer $j$ is in working order and a minimum of $i-1$ of the rest are operational. The beginning and end conditions of (7) are $R^{(0, j)}=1$ and $R^{(j+1, j)}=0$. This algorithm reduces the analysis for a system of up to $m$ failures from a population of $N$ transformers to the order of $N \times m$ operations [11], [13]. Moreover, the results for up to $m-1$, $m-2$, etc. are directly available as an intermediate result of the recurrent analysis. With (7) the mean-time-to-failure (MTTF) of the failure of $m$ transformers, $\mathrm{MTTF}_{m}$ is

$$
\mathrm{MTTF}_{m}=\int_{0}^{\infty} R^{(N-m+1, N)}(t) d t .
$$

Equation (8) links the time with population reliability. The population reliability $R_{P}$ belonging to the $\mathrm{MTTF}_{m}$ is defined as

$$
R_{P}\left(t=\mathrm{MTTF}_{m}\right)=\frac{N-m}{N} .
$$

\section{B. Transformer Fleet Example}

Large-scale electrification in The Netherlands took place between 1960 and 1980. The installation dates of the combined population of two utilities consisting of 579 distribution transformers are depicted in Fig. 3. The population model is applied to investigate whether utilities have to be prepared for a failure wave of power transformers in the near future. The installation distribution, more or less normally distributed around 1973 with a standard deviation of 12 years, may result in a peaked future failure rate as well. The IEC transformer design guide [14] assumes a life span of 40 years under nominal loading conditions. If this were the case, a failure wave could be expected between 2010 and 2020, assuming all transformers are nominally loaded. In order to make precise predictions, the actual loads and load cycles of individual transformers must be incorporated. Further, the load is expected to gradually increase in the future. An average yearly growth of about $2 \%$ is observed for The Netherlands over the period 1998-2008 according to the statistics in [15].

As a failure mechanism, the paper degradation model discussed in Section II-A is taken for each individual transformer. Many transformers lack precise historical data and assumptions have to be made. For the modeling parameters, the following conditions are taken:

- installation date and cooling method is available from the database;

- ambient temperature is taken according to the average values;

- historical load pattern is used and a regular increase in load is assumed; 


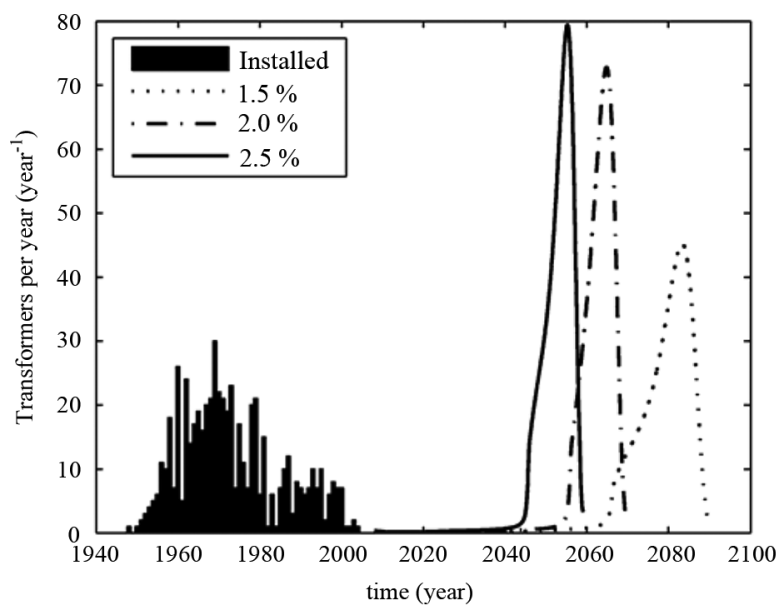

(a)

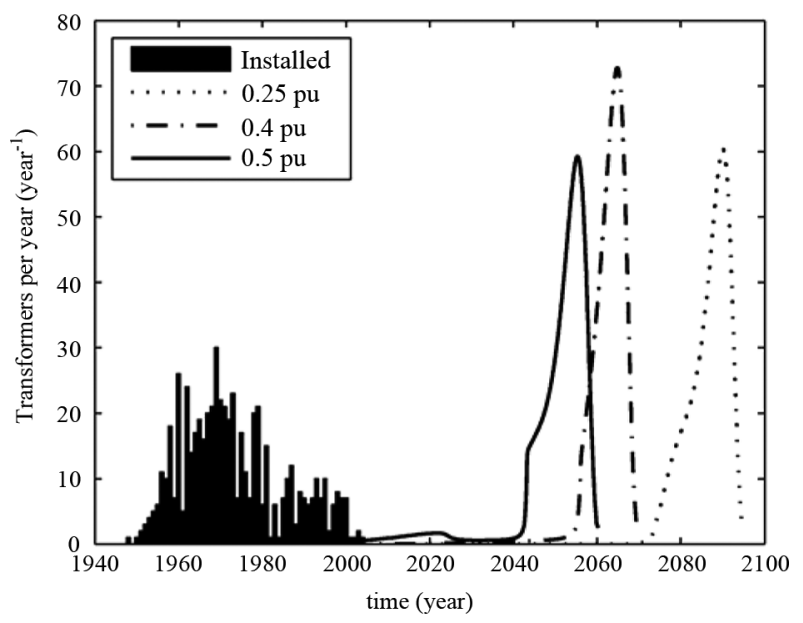

(b)

Fig. 3. Transformer installation dates for 579 installed transformers of two utilities (bars), together with their expected failure waves, for (a) a load growth of $1.5 \%, 2 \%$, and $2.5 \%$, and (b) for an initial load of $0.25,0.4$, and 0.5 p.u.

- the accuracy of all input parameters is taken as 5\% of their actual value, except for the load which is taken as $10 \%$;

- all transformers are located outside and are cooled by wind;

- transformers are continuously in operation.

The year of installation and the cooling modes is extracted from the combined population databases. From these populations, next to the installation time, the cooling modes: oil-natural-air-natural (ONAN), oil-natural-air-forced (ONAF), oil-forced (OF), and oil-directed (OD) are used as input parameters. The transformer parameters belonging to the cooling modes are derived from the former current IEC loading guide [8]. For the ambient temperature $\theta_{a}$, the temperature model of the IEC loading guide [16] is used

$$
\begin{aligned}
& \theta_{a}(t)=\theta_{a y}+A_{1} \cos \left[\frac{2 \pi}{24 \cdot 365}\right.\left.\left(t-24 \varphi_{1}\right)\right] \\
&+A_{2} \cos \left[\frac{2 \pi}{24}\left(t-\varphi_{2}\right)\right]
\end{aligned}
$$

with $t$ in hours. The constants in (10) are $\theta_{a y}=9.4^{\circ} \mathrm{C}, A_{1}=$ $7.4^{\circ} \mathrm{C}, \varphi_{1}=199$ days, $A_{2}=13{ }^{\circ} \mathrm{C}$, and $\varphi_{2}=15 \mathrm{~h}$ based on historical outside temperature averages. The current yearly load growth is about $2 \%$. To obtain the per-unit load, the average for
TABLE III

Peak AND Standard DeViation of ExPected Failure WaVe For a LoAd GROWTH OF $1.5 \%, 2 \%, 2.5 \%$, AND FOR 0.25, 0.4, AND 0.5 p.u. LOAD IN 2008

\begin{tabular}{cccc}
\hline Scenario & & Peak year & St.dev. \\
\hline \multirow{3}{*}{ Load growth } & $1.5 \%$ & 2079 & 8 \\
& $2.0 \%$ & 2063 & 5 \\
& $2.5 \%$ & 2053 & 5 \\
\hline \multirow{3}{*}{ Initial Load } & 0.25 p.u. & 2087 & 6 \\
& 0.40 p.u. & 2063 & 5 \\
& 0.50 p.u. & 2050 & 10 \\
\hline
\end{tabular}

every hour in the period 2003-2006 is calculated. This average is taken for the (reference) year 2008 and every hourly value is then normalized so that the maximum hourly value occurring throughout a year corresponds to a per-unit load of 0.4. The impact of the load growth assumption and the initial load condition are demonstrated by simulations, where these parameters are varied separately.

One of the critical assumptions is the annual load growth. As a reference, a value of $2 \%$ is chosen. In order to determine the sensitivity of the failure wave with respect to the load growth, this parameter is varied. The results are summarized in Table III, and the corresponding graphs are plotted in Fig. 3(a). A 2\% load growth results in a failure peak around the year 2063. A $0.5 \%$ lower or higher value shifts the peak 10 years forward or 15 years backwards, respectively. Furthermore, the peak narrows. This is related to accelerated aging, when the rated transformer power is approached. This occurs for every transformer at the same moment, since all of them are assumed to have equal load in the reference year. The sensitivity with respect to the initial load is investigated for a fixed load growth of $2 \%$. Three load patterns were applied, the original value of 0.4 p.u. and the loads where the maximum is scaled to 0.25 p.u. and 0.5 p.u. The results of these simulations are provided in Table III and in Fig. 3(b). Next to the observation that the lifespan gets shorter with increasing load, it is observed that there is a combined effect of load growth and initial load. An exponential growth tends to disguise the original population distribution, especially at low initial load since all transformers reach their rated power in a relatively short time. If the initial load is already close to the nominal per-unit load, the initial age distribution is more or less conserved.

\section{RePlacement Alternatives}

The transformer population model not only aims to predict future failure rates, but also to analyze the effectiveness of maintenance/replacement strategies. Two case studies are presented. The first example studies the effect of a few hypothetical replacement approaches on the distribution transformer population discussed in Section III-B. The second example investigates the effects on a small population of transformers from which the load history is available.

\section{A. Transformer Fleet Example}

This simplified alternative addresses a mitigation action, where any endangered transformer gets assistance in the form of load sharing with a new additional transformer. The model allows investigating the effect of upgrading a yearly number of transformers which have the highest failure probability. As an 


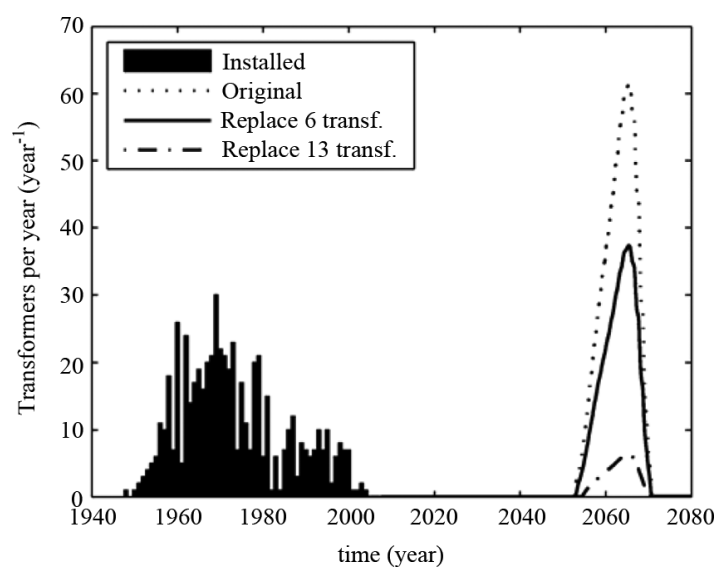

Fig. 4. Replacement wave with a $2 \%$ annual load growth without measure (dotted line), and with annually upgrading six transformers (solid line) or thirteen transformers (dashed-dotted line).

example, annually six transformers are added to the existing assets to relieve transformers that are expected to have aged considerably. The selection process takes place over a period of 40 years starting in 2009. An initial load of 0.4 p.u. and an annual load growth of $2 \%$ is assumed. In the transformer failure distribution of Fig. 4, it has been seen that the replacement alternative (solid line) results in a reduction and a slight shift of the original replacement probability (dotted line).

There is no preference in the order where to install the first new transformers. This is related to the equal load assumption taken for all transformers. No efficient selection of transformers to be replaced can be made. Only with an extensive monitoring program of the DP value, a transformer selection scheme might be possible. If not, the number of transformers to be added yearly must be of the order of the total number of transformers involved divided by the expected duration up to the expected replacement peak [i.e., about 13 transformers per year (dasheddotted line in Fig. 4)].

The load of transformers depends on the region they are situated and on the type of users which are connected. The "equal load" assumption is only achieved when transformers would be permutated between substations with relatively large and low load. Even then, the replacement wave would start earlier due to the nonlinear response of aging upon load compared to constant equal loading. In this example, the load growth percentage is varied to enforce diversity in the individual loading scenarios. Five groups of different load growth percentages are formed with an almost equal number of transformers. The load growth percentages are between $1.8 \%$ and $2.2 \%$ with steps of $0.1 \%$. All other assumptions are kept the same. Further, annually six most aged transformers get load sharing, which reduce their load by a factor two. The results are plotted in Fig. 5. Observations can be made as follows.

- Compared to the fixed $2 \%$ load growth simulation for all transformers (dashed line), the distributed growth rate (solid line) causes a broadening in Fig. 5 and a drop of the peak from 60 to 40 transformers per year. Transformers with high load growth tend to fail earlier and transformers with a relative low growth in load later.

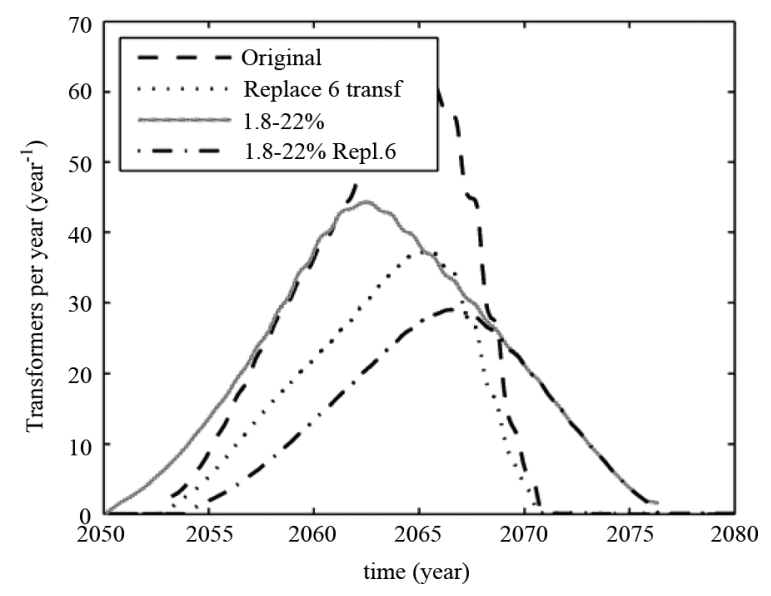

Fig. 5. Replacement wave with a fixed $2 \%$ annual load growth without and with annually upgrading six transformers, and replacement waves including a variation of annual load between 1.8 and $2.2 \%$.

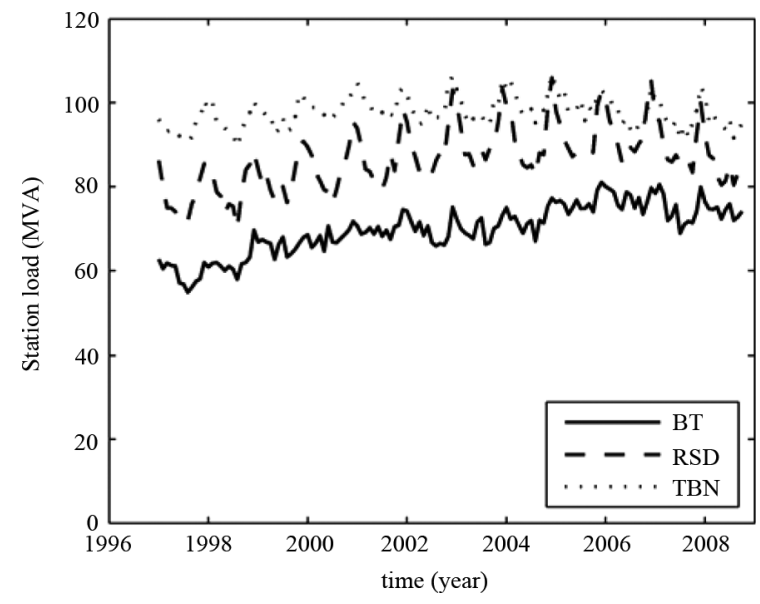

Fig. 6. Monthly load maxima of three substations over a 12-year period.

- If the policy of six additional transformers is applied, again a broader distribution is obtained for the 1.8\%-2.2\% load growth situation (dashed-dotted line) compared to the equal growth (dotted line); however, the peak has completely shifted, indicating that now transformers can be effectively selected.

- With distributed load growth, the replacement strategy of six annual transformers (shift of the solid line to the dashed-dotted line) is far more efficient than in an equal load situation (the shift of the dashed line to the dotted line).

\section{B. Three Substation Example}

The load of every individual transformer from three Dutch substations, each with three transformers, has been logged every $5 \mathrm{~min}$ in the year 2008 and their monthly maximum load values are logged over 12 years. The load values, depicted in Fig. 6, are used to determine the annual load growth percentage by linear regression, resulting in an average of about $1 \%$ yearly load growth for the 1996-2008 period. The 2008 individual transformer load is extrapolated for the remaining years with a load growth of $1 \%$. 
TABLE IV

PARAMETERS OF TRANSFORMERS IN THREE SELECTED SubSTATIONS: ALL TRANSFORMERS ARE IN ONAF OPERATION, WITH $x=0.8, y=1.3, T_{0}=$ $150 \mathrm{~min}, T_{w}=7 \mathrm{~min}, c_{11}=0.5, c_{21}=2$, AND $c_{22}=2 ; \sigma$-VALUES OF ALL PARAMETERS ARE ASSUMED 5\% OF THE MEAN

\begin{tabular}{ccccccc}
\hline $\begin{array}{c}\text { Subst. } \\
\text { transf. }\end{array}$ & $\begin{array}{c}\text { Year of } \\
\text { install. }\end{array}$ & $\begin{array}{c}\text { Power } \\
\text { (MVA) }\end{array}$ & $R$ & $\begin{array}{c}\Delta \theta_{o r} \\
\left({ }^{\circ} \mathrm{C}\right)\end{array}$ & $\begin{array}{c}\Delta \theta_{h r} \\
\left({ }^{\circ} \mathrm{C}\right)\end{array}$ & $\begin{array}{c}\text { Online } \\
\text { perc. }\end{array}$ \\
\hline BT1 & 1972 & & 6.0 & & & 72 \\
BT2 & 1973 & 44 & 6.1 & 54.1 & 26.7 & 58 \\
BT3 & 1975 & & 6.7 & & & 70 \\
\hline RSD1 & 1995 & & 5.4 & & & 72 \\
RSD2 & 1993 & 63 & 5.4 & 57.7 & 22.5 & 54 \\
RSD3 & 1993 & & 5.6 & & & 73 \\
\hline TBN1 & 1976 & & 7.1 & & & 61 \\
TBN2 & 1976 & 77 & 6.6 & 55.7 & 26.0 & 55 \\
TBN3 & 1976 & & 7.2 & & & 85 \\
\hline
\end{tabular}

The transformer data as summarized in Table IV are extracted from the manufacturer's test reports. The dynamic temperature model is taken from [8] and [17] and is summarized in the Appendix. The degradation parameters of the applied Kraft paper are taken from Table II (Kraft, [6]). The ambient temperature of all transformers is assumed to follow the temperature model of the former IEC loading guide [16] as expressed in (10).

Each substation contains two busbars with each a connected transformer. The third transformer is only connected when one of the others is in maintenance. Since the busbars have unequal load and the spare transformer is only occasionally in operation, the expected remaining transformer lifetimes differ. These individual lifetimes are calculated and combined to a population reliability distribution. This distribution and its reliability density function are plotted in Fig. 7 (solid lines). An equally shared load over all transformers in each substation is expected to result in a more efficient usage of the assets. To this end, the present loading strategy is compared to a shared load. Consider a hypothetical situation, where as from 2009 the two active transformers share equally the load of both busbars. Further, a rotating scheme is adopted for the third transformer so that over longer time, all transformers are equally loaded. The result of this equal load scenario (dotted lines) is a steeper decline of the reliability and a delay of the first failure. The expected time of first failure is delayed by almost ten years and all transformers are expected to fail in half of the original time span.

\section{DISCUSSION}

From the annual replacement strategies of Section IV-A, it can be observed that the equal load is most unfavorable since there is no preference in the order of replacement, except for the installation date. The installation date, however, may hardly be reflected in the end-of-life distribution. Further, it can be seen that for a preventive replacement of all transformers, the transformers need to be replaced before the beginning of the failure wave. A variation in load growth percentage between transformers leads to a spread of the replacement wave. As further optimization, one could consider having a dynamic replacement strategy starting with less replacement per year, but after some time, this value is increased. Failure of transformers in
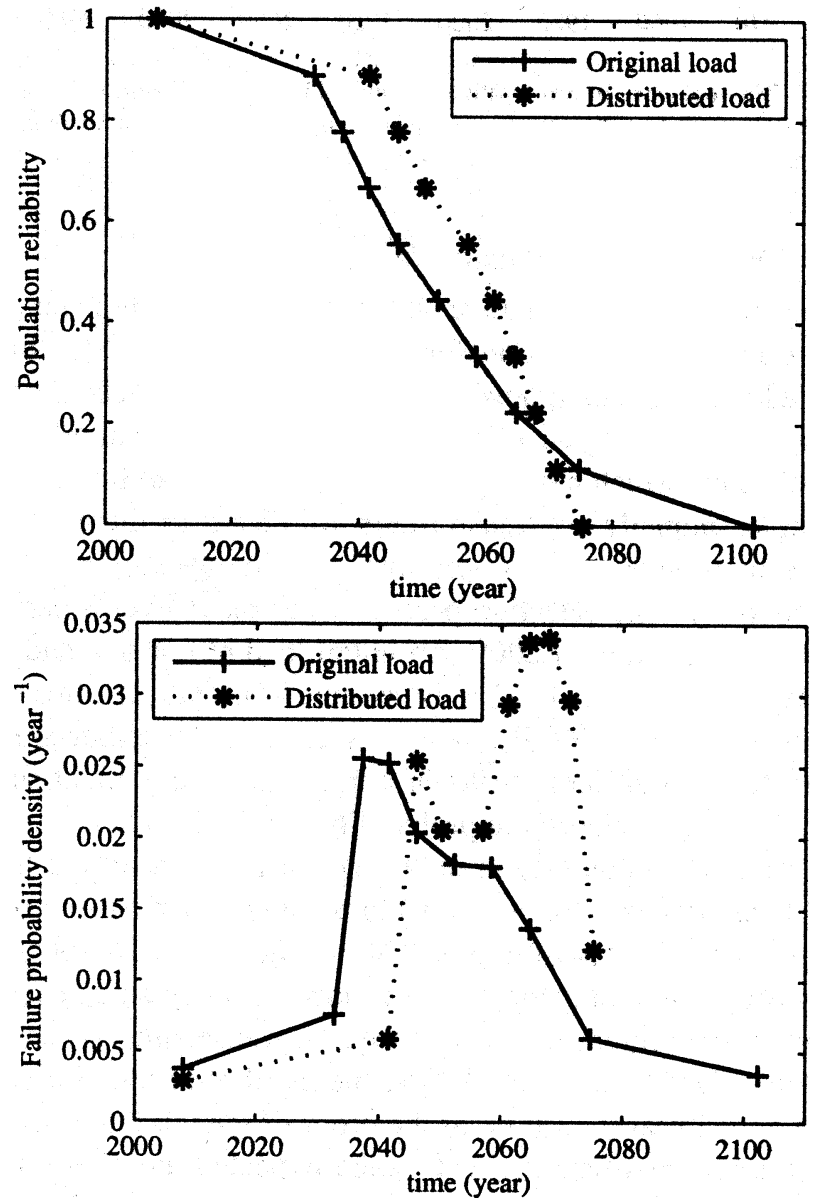

Fig. 7. Fleet reliability (top) and probability density function (bottom) of nine transformers in three substations. The solid line represents the original load situation. The dotted line represents the reliability of the substation, with two transformers equally loaded and using a rotation scheme.

the three substations could be delayed by a rotating scheme, so they share more or less equal load. The negative effect is that the transformers will fail in a shorter time span.

Apparently, it is more favorable to have transformers with a significant loss of life before adding an extra transformer than trying to obtain an equal load as much as possible. Judgment of these strategies not only involves a technical reliability model, but requires a complete asset-management approach of which the technical model is a small, but crucial, part. The strategy of spreading the expected replacement wave over a manageable time period faces a difficult selection mechanism, depending heavily on correct information. The information needed for selecting the right set of transformers to be replaced is historical load, historical fault, and failure situations, future load scenarios, future stresses, and maintenance schemes. The benefit of a fixed number of annual replacements is that they are relatively easy to manage. The obvious downside is the fact that the components are not used for their maximum operational life. However, depending on the replacement policy, the maximum utilization by having equal loads for all assets is not necessarily the best strategy economically. 


\section{CONCLUSION}

A technical reliability model is discussed from which remaining lifetimes of a transformer population can be obtained. This model enables determining the effect of various replacement strategies in terms of reliability. For the optimal replacement and maintenance strategy, the technical reliability model must be incorporated in an integral asset-management decision model, which is out of the scope of this paper. This general model is fed by the output of a technical model as presented here.

The technical reliability model for the transformer (Section II) predicts key values such as DP value, hotspot, and top-oil temperature with the aid of a degradation mechanism model. The benefits of this approach are: 1) the physical processes provide means for long-term prediction and 2) the key values provide feedback about the quality of the model and its parameters.

The transformer reliabilities can be combined in a reliability model for a population of transformers (Section III). It was shown that population characteristics enable judging the consequences of replacement strategies (e.g., to mitigate replacement waves). The model is able to deal with a population of components with diverse individual reliabilities. Populations of a thousand assets can still be effectively dealt with. For larger populations, groups of transformers will have similar parameters, and they can be combined and modeled by single reliabilities. This reduces computation time and reduces the effort to provide all information.

Models predicting future reliability suffer from dependence on available data of the assets. In the presented model, this is partly circumvented by the probabilistic approach. Uncertainties in the input data translate to uncertainties in the predictions, which are accounted for. The parameter uncertainties chosen for the simulation are sometimes rough estimates. Despite these uncertainties, the response on different maintenance and replacement actions can still be compared. Moreover, from the model, the most critical factors determining the uncertainty can be retrieved.

To increase accuracy, parameters can be monitored that are related to uncertain factors. For instance, if the actual DP value of a transformer is retrieved (with some error bound), better predictions can be made. The model can be calibrated from this point onwards. In addition, from the measurement parameter values, describing the paper degradation process and their error bounds can be determined with higher accuracy.

\section{APPENDIX}

The top-oil temperature $\theta_{0}$ and the hotspot temperatures $\theta_{h}$ can be described with a set of three differential equations according to IEC 60076-7 [8] and [17], [18]. The time derivative of the top-oil temperature contains a heating part due to the current $I$, using an average time response of the oil $\tau_{0}$ and a term which involves the heat loss driven by the difference between top-oil temperature and ambient temperature $\theta_{a}$. The top-oil temperature is given by

$$
\dot{\theta}_{0}=\frac{1}{c_{11} \tau_{0}}\left(\Delta \theta_{0 r}\left(\frac{1+I^{2} R}{1+R}\right)^{x}-\left(\theta_{0}-\theta_{a}\right)\right)
$$

where $\Delta \theta_{0 r}$ is the top-oil temperature rise in steady state for the rated current. $R$ represents the ratio of load losses at rated current to no-load losses. Power $x$ is the exponential power of total losses versus top-oil temperature rise in steady state, and $c_{11}$ is a correction factor on the average oil response time $\tau_{0}$. The hotspot gradient temperature represents the temperature rise at the windings due to heat generated in the windings and incorporates the different response times of the heat transported through the windings and oil. It can be split in a part accounting for the winding response time and for the oil response time. At rated current, the hotspot-to-top-oil gradient is $\Delta \theta_{h r}$ and $y$ is the power of current versus winding temperature rise in steady state. The term corresponding with the winding response $\theta_{h 1, g r}$ can be expressed as

$$
\dot{\theta}_{h 1, g r}=\frac{1}{c_{22} \tau_{w}}\left(c_{21} \Delta \theta_{h r} I^{y}-\theta_{h 1, g r}\right)
$$

with $\tau_{w}$ the winding response time and $c_{21}$ being a factor related to which portion of the heating is due to the winding or to the oil. Factor $c_{22}$ is a general thermal correction factor. The hotspot oil temperature gradient $\theta_{h 2, g r}$ is given by

$$
\dot{\theta}_{h 2, g r}=\frac{c_{21}}{\tau_{0}}\left(\left(c_{21}-1\right) \Delta \theta_{h r} I^{y}-\theta_{h 2, g r}\right) .
$$

The hotspot temperature $\theta_{h}$ follows from the top-oil temperature and hotspot-to-top-oil gradient at the load considered

$$
\theta_{h}=\theta_{0}+\Delta \theta_{h} \quad \text { with } \quad \Delta \theta_{h}=\theta_{h 1, g r}-\theta_{h 2, g r} .
$$

\section{ACKNOWLEDGMENT}

The authors would like to thank H. Verhaart (KEMA Nederland B.V.), M. Berende (Enexis B.V.), and H. Arts (Stedin B.V.) for their contributions.

\section{REFERENCES}

[1] A. van Schijndel, J. M. Wetzer, and P. A. A. F. Wouters, "Forecasting transformer reliability," in Proc. IEEE Conf. Electr. Insul. Dielectr. Phenom., Kansas City, MO, Oct. 2006, pp. 577-582.

[2] V. M. Montsinger, "Loading transformers by temperature," AIEE Trans., vol. 49, pp. 776-792, 1930.

[3] D. H. Shroff and A. W. Stannett, "A review of paper aging in power transformers," Proc. Inst. Elect. Eng., Gen. Transm. Distrib., vol. 132, no. 6, pp. 312-319, Nov. 1985.

[4] A. M. Emsley and G. C. Stevens, "Review of chemical indicators of degradation of cellulosic electrical paper insulation in oil-filled transformers," Proc. Inst. Elect. Eng., Sci. Meas. Technol., vol. 141, no. 5, pp. 324-334, Sep. 1994

[5] A. M. Emsley, R. J. Heywood, M. Ali, and X. Xiao, "Degradation of cellulosic insulation in power transformers. Part 4: Effects of ageing on the tensile strength of paper," Proc. Inst. Elect. Eng., Sci. Meas. Technol., vol. 147, no. 6, pp. 285-290, Nov. 2000. 
[6] L. E. Lundgaard, W. Hansen, D. Linhjell, and T. J. Painter, "Aging of oil-impregnated paper in power transformers," IEEE Trans. Power Del., vol. 19, no. 1, pp. 230-239, Jan. 2004.

[7] CIGRÉ 323, Aging of cellulose in mineral-oil insulated transformers, CIGRÉ Rep., 2007.

[8] Power Transformers-Part 7: Loading Guide for Oil-Immersed Power Transformers, IEC 60076-7, 2005.

[9] "IEEE Guide for Loading Mineral-Oil-Immersed Transformers," IEEE, 1996, IEEE C57.91-1995.

[10] A. v. Schijndel, P. A. A. F. Wouters, E. F. Steennis, and J. M. Wetzer, "Approach for an integral power transformer reliability model," Eur. Trans. Elect. Power, 2011.

[11] A. v. Schijndel, J. M. Wetzer, and P. A. A. F. Wouters, "Modelling technique for power transformer replacement waves," presented at the 10th Int. Conf. Prob. Meth. Appl. Power Syst., Mayagüez, Puerto Rico, May 2008.

[12] A. v. Schijndel, J. M. Wetzer, and P. A. A. F. Wouters, "Forecasting reliability of transformer populations," presented at the 19th Int. Conf. Electr. Distrib., Vienna, Austria, May 2007.

[13] W. Kuo and M. J. Zou, Optimal Reliability Modeling. Hoboken, NJ: Wiley, 2003.

[14] Power transformers-Part 14: Design and Application of Liquid-Immersed Power Transformers Using High-Temperature Insulation Materials, IEC 60076-14, IEC, 2009, 2.0 ed.

[15] U.S. Energy Information Admin. [Online]. Available: http://www.eia. gov/

[16] Loading Guide for Oil-Immersed Power Transformers, IEC 60354, IEC, 1991.

[17] H. Nordman, N. Rafsback, and D. Susa, "Temperature responses to step changes in the load current of power transformers," IEEE Trans. Power Del., vol. 18 , no. 4, pp. 1110-1117, Oct. 2003.

[18] D. Susa, "Dynamic thermal modelling of power transformers," Ph.D. dissertation, Dept. Elect. Commun. Eng., Helsinki Univ. Technol., Espoo, Finland, 2005.

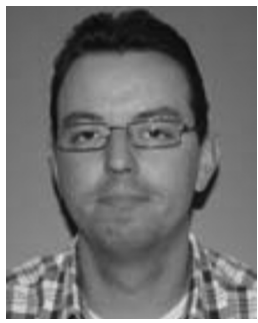

Arjan van Schijndel (S'06) was born in Oss, The Netherlands, on February 9, 1978. He received the M.Sc. degree in electrical engineering and the Ph.D. degree in power transformer reliability modeling from the Eindhoven University of Technology, Eindhoven, The Netherlands, in 2004 and 2010, respectively.

His current research mainly deals with developing an integral lifetime model for power transformers. His research interests include antenna modeling, electromagnetic-field screening, and reliability

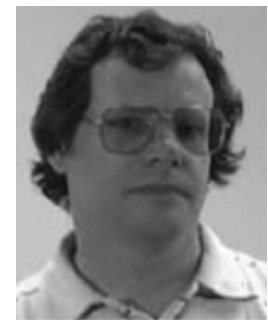

Peter A. A. F. Wouters was born in Eindhoven, the Netherlands, on June 9, 1957. He received the Ph.D. degree for a study on elementary electronic transitions between metal surfaces and low energetic (multiple) charged ions from Utrecht University (UU), Utrecht, The Netherlands, in 1989.

In 1990, he joined the Electrical Energy Systems (EES) Group at the Technical University of Eindhoven, Eindhoven, as Research Associate. Currently, he is Assistant Professor in the field of diagnostic techniques in high-voltage systems. His research interests include partial-discharge techniques, vacuum insulation, and LF electromagnetic-field screening.

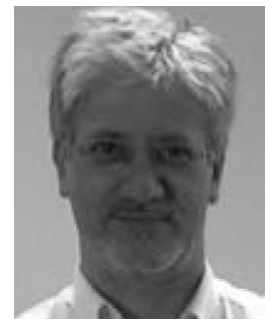

Joseph M. Wetzer was born on August 21, 1955 in The Netherlands. He received the M.Sc. degree in electrical engineering and the $\mathrm{Ph} . \mathrm{D}$. degree in technical sciences from the Eindhoven University of Technology, Eindhoven, The Netherlands, in 1984.

After he received the Ph.D. degree, he became Associate Professor at the Eindhoven University of Technology for 14 years. His activities included research, education, and consultancy in the field of high-voltage engineering and electromagnetic compatibility (EMC). In 1998, he joined KEMA as a Senior Consultant in the field of condition assessment, asset management, and EMC. From 2001 to 2006, he has held a management position. From 2004 to 2007, he was a Part-Time Professor with the Eindhoven University of Technology, engaged in asset management of electrical infrastructures. He is Principal Consultant with KEMA Nederland B.V, Arnhem, The Netherlands. He has been published in many scientific and professional publications. His expertise includes asset and maintenance management, condition assessment and diagnostics, dielectrics and electrical insulation, electromagnetic fields, and EMC.

engineering. 